\title{
Fichas pedagógicas: propuesta metodológica para enseñar el idioma español y la cultura costarricense a estudiantes extranjeros
}

Br. Álvaro Morales Calderón

El aprendizaje de una lengua extranjera no sólo se limita a adquirir contenidos gramaticales, ortográficos y de buena pronunciación; sino que va más allá del campo lingüístico. Este proceso implica, también, la adquisición de los gestos (kinésica), los comportamientos y las manifestaciones culturales del país donde se habla la lengua. Es difícil enseñar español y dejar de lado la cultura de nuestro país. Por tanto, es necesario que el aprendiz interiorice este nuevo universo de costumbres, tradiciones y legados propios de una nueva cultura. La tarea no es fácil, sin embargo, el profesor debe promover e integrar esta nueva práctica en los cursos de lengua extranjera. El desarrollo de la competencia cultural, en clase de lengua extranjera, es tan esencial como desarrollar, en el estudiante, las diferentes destrezas. De esta manera, el aprendiz puede ir asimilando e integrando la parte cultural para lograr un conocimiento 
mayor, no únicamente de la lengua, sino también de los aspectos culturales que han influido en la conformación de la comunidad, en la que es hablada la lengua.

Los aspectos culturales de un país son muy variados y difíciles de integrar en un solo curso de lengua extranjera, por tal razón se debe privilegiar temas representativos del país que permitan desarrollar algunos de los contenidos culturales. Una vez seleccionado el tema, es necesario preparar y elaborar material apropiado, con el fin de llevar a cabo las actividades de carácter cultural, $y$, de esta manera, integrarlas al aprendizaje de la lengua meta.

Muchas veces, los profesores de lengua extranjera temen abordar y desarrollar aspectos culturales debido a que algunos estudiantes no están interesados en aprender cuestiones relacionadas con la cultura, o bien existe un desconocimiento de información y de preparación por parte de los docentes; ellos consideran que la cultura no es fácil de enseñar y que implica un amplio conocimiento de temas relacionados con el quehacer cultural. Estos son algunos motivos por los que se obvia la inserción de lo cultural en las clases de lengua y se limitan a la enseñanza de los contenidos lingüísticos. Sin embargo, la enseñanza de la cultura se puede hacer de una forma sencilla, agradable y creativa; con técnicas, estrategias y actividades que permitan un acceso integral a la lengua meta y a su cultura. Desde este punto de vista, lo cultural se va a unir con los contenidos lingüísticos en el proceso de aprendizaje e involucra tanto al docente como al discente.

El término cultura es un concepto que se ha manejado desde las épocas más antiguas: se habla de las culturas griega, romana, egipcia, entre otras, y hasta de la cultura del pueblo situado en el lugar más lejano de nuestro país. La cultura implica todos los elementos adquiridos, utilizados y transmitidos de generación en generación, y que 
configuran la herencia y el patrimonio de un país o de una sociedad.

La cultura de un pueblo, de alguna forma, ha sufrido cambios y hasta la influencia de otras culturas, por lo que, algunas veces, evoluciona con el pasar del tiempo. Sin embargo, cada pueblo, cada país o cada sociedad trata de guardar, con ahínco, sus creencias, sus costumbres y los valores que han prevalecido con el correr de los años, a lo largo de su historia.

Costa Rica atesora su gran riqueza cultural, de la misma manera que se mantienen sus tradiciones, sus legados y sus valores. Los costarricenses somos parte de la gran familia hispánica, unida por la lengua de Cervantes. Sin embargo, rasgos especiales caracterizan esta lengua de los costarricenses y decimos la "galletica", el "confitico", el "ratico" y por eso somos los TICOS. Estamos orgullosos de poder compartir nuestras costumbres, creencias y tradiciones con quienes se interesan por aprender nuestra lengua, y descubrir nuestra cultura... ¡con mucho gusto!

Costa Rica no solamente ha sido reconocida en el mundo por la paz, sino también por sus grandes logros en literatura, pintura, escultura, folclor, artesanía, grupos indígenas, centros culturales, y hasta en el ecoturismo, una de las principales fuentes de atracción turística. Cada día son más los extranjeros que nos visitan, con el objetivo de aprender español y de conocer parte de la idiosincrasia del costarricense. Por esta razón, la enseñanza del español como segunda lengua se ha intensificado y fortalecido en nuestro país, el cual es preferido entre muchas regiones del mundo.

Esto significa un gran compromiso para con los estudiantes extranjeros, quienes con esfuerzo y entusiasmo hacen su inmersión en el aprendizaje de nuestra lengua y de nuestra cultura. ¿No somos acaso los profesores de lengua, los embajadores de nuestro idioma y de nuestra cultura? 
En la práctica pedagógica de las clases de español es importante que los estudiantes reconozcan la diferencia entre los verbos "ser" y "estar"; y que los utilicen apropiadamente; por ejemplo, explicarle a un francés, quien posee solamente una forma verbal "être" para decir: "je suis français" o "je suis fatigué" (yo soy francés o yo estoy cansado); pero, al mismo tiempo, a ese aprendizaje lingüístico, también, es importante agregarle algún aspecto cultural y explicar que en Costa Rica no se come "camembert"; sino que los costarricenses comen queso tierno y desayunan gallo pinto.

Los nativos adquirimos la cultura de manera inconsciente o de manera natural, debido a que vivimos en ella. Por el contrario, los extranjeros aprenden esta cultura de manera escolarizada (si no están en inmersión). Sin embargo, estos aspectos de la cultura pueden ser enfrentados utilizando la misma lengua. Desde este punto de vista, se puede decir que la lengua es el objeto de estudio y, a la vez, el instrumento que sirve para el descubrimiento, la descripción y la adquisición de la cultura.

Los diferentes contenidos propios de la cultura no aparecen en los manuales o en los métodos para enseñar español, ya sea como lengua extranjera o como segunda lengua; y a pesar del ingenio y la creatividad que poseen los profesores de lenguas extranjeras; algunas veces, se dificulta la preparación de actividades pedagógicas, en las cuales se tome en cuenta lo lingüístico y como parte esencial de la actividad se integre, también, algún aspecto de la cultura.

Con el fin de facilitar ese soporte didáctico que integre los aspectos culturales, junto con objetivos lingüísticos y con una metodología apropiada a la enseñanza de la lengua, nace la propuesta de la elaboración de fichas pedagógicas como una herramienta para la enseñanza del español. 
La ficha pedagógica es una herramienta que permite planear y desarrollar, ágilmente, actividades para el aprendizaje de algún tema de forma ordenada, dinámica y motivadora para los estudiantes. Este instrumento pedagógico permite preparar temas de interés colectivo, confrontar posibles dificultades y, al mismo tiempo, dar respuestas de una manera clara y original, al abordaje de un aspecto cultural específico.

La ficha pedagógica propone un tema, con el cual interrelaciona el objetivo lingüístico, el objetivo comunicativo y el objetivo cultural. Otro elemento a tener en cuenta es el público: niños, adolescentes, adultos. También el nivel y los intereses de los estudiantes. Para determinar el nivel en el que se utilizará la ficha pedagógica, haré referencia al Marco Común Europeo de Referencia para las Lenguas (MCER). El Marco Común describe las actividades de la ficha pedagógica de acuerdo a sus descriptores que determinarán la competencia y destrezas comunicativas de los estudiantes. El MCER permite describir el dominio lingüístico y define el tipo de usuario, entre los que están: el usuario "básico" con nivel A1 (acceso) y A2 (plataforma), el usuario independiente con nivel B1 (umbral) y B2 (avanzado) y el usuario competente con nivel C1 (dominio operativo eficaz) y C2 (maestría).

Una vez determinado el nivel, se selecciona el objetivo lingüístico que es uno de los componentes principales de la enseñanza de lenguas. El objetivo contempla elementos tales como: producir un enunciado con los tiempos verbales correctos, el orden adecuado de los elementos que constituyen la frase, el léxico. Por ejemplo, si se trabaja un documento relacionado con la gastronomía, se enriquece el léxico de comidas, frutas, verduras, vegetales, especias y otros más. Además, se podrá realizar la descripción de platos típicos. 
Otro elemento a establecer es el objetivo comunicativo el cual persigue y provoca la reacción comunicativa del alumno. El objetivo comunicativo desarrolla la interacción y el uso de la lengua meta, con el propósito de que el estudiante transmita su mensaje, exprese sus ideas, aun cuando existan errores y no haya una autocorrección. Retomemos el ejemplo anterior sobre la gastronomía: podríamos relacionar el objetivo comunicativo con la expresión de nuestras preferencias por la comida, por ejemplo, qué me gusta y qué me disgusta.

En interacción con los dos objetivos antes descritos, se asocia el objetivo cultural. Este objetivo permite descubrir una nueva realidad y abrir las puertas a la interculturalidad. Los elementos culturales se podrán desarrollar con una mutualidad de saberes y de conocimientos, que favorezcan el intercambio de la nueva cultura con la cultura propia de cada uno de los estudiantes. El tema de la gastronomía nos permitirá realizar una pequeña actividad o feria en la que se expongan platos típicos, recetas de los diferentes países, música y más. De esta manera, se promueven nuevas experiencias y el acercamiento con personas de diferentes partes del hemisferio o del globo.

Es importante no perder de vista el tiempo para realizar la actividad. El buen manejo de cada minuto con el que se cuenta ayuda a desarrollar y controlar mejor cada actividad.

Los elementos anteriores permiten la confección de una adecuada ficha pedagógica. Además, es primordial explicitar las instrucciones de la propuesta y el procedimiento de la ficha pedagógica, debe utilizarse un estilo directo y evite aspectos muy teóricos; esto ayudará a una mejor comprensión e implementación por parte de las personas que la utilicen. El material necesario y la disposición de la clase deben indicarse para completar la ficha pedagógica.

Esta herramienta pedagógica desarrolla la competencia cultural de una comunidad lingüística, sin dejar de lado 
la competencia comunicativa del estudiante. La perspectiva sociocultural, compartida con los aspectos comunicativos, armoniza y equilibra el aprendizaje de la lengua meta. Estos dos elementos sensibilizan a los estudiantes y los preparan para descubrir diferentes aspectos de la cultura, así como los estereotipos y, en la medida de la progresión de la lengua, trabajar más a fondo la reflexión de los temas propuestos.

Para llevar a cabo un buen trabajo, se necesita explotar cualquier tipo de material, por muy variado, sencillo o corriente que sea, así como textos auténticos que formen parte de nuestra identidad cultural, y aprovechar la experiencia de nuestra visión de mundo y del conocimiento adquirido en el seno de nuestra comunidad maternal.

Cada ficha pedagógica debe proponer una serie de recursos concretos aplicados a las habilidades comunicativas que permitan desarrollar la dimensión cultural. La aplicación de estos recursos avanza progresivamente, y permite diagnosticar la evolución del estudiante en el proceso adquisitivo de la lengua meta. De esta forma, el profesor valora los conocimientos, reafirma lo adquirido, corrige errores y aclara dudas; acciones que sirven para mejorar el aprendizaje de la lengua de manera contextualizada, sin dejar de lado el eje cultural. Cada estudiante adquiere el bagaje cultural, que le permite determinar su participación en la cotidianidad y el dominio de sus destrezas lingüísticas.

La clase de lengua debe ser el lugar privilegiado donde se analicen aspectos culturales, entre la cultura de la lengua materna y de las lenguas extranjeras; provocando el interés y el aprendizaje de la forma de percibir las diferencias, alrededor de las cuales giran las distintas sociedades a las que pertenecemos los seres humanos.

Desde esta perspectiva, la enseñanza de la cultura juega un papel primordial en las clases de lengua extranjera. Las fichas pedagógicas como herramienta de aprendizaje, 
ayudan al docente y al discente para transmitir y adquirir nuestra cultura. El aula debe convertirse en el centro de actividades donde se proyecte el quehacer cultural de nuestro país.

El material de la propuesta de las fichas pedagógicas debe presentar un amplio panorama de las costumbres, las tradiciones y la idiosincrasia del costarricense. Los conocimientos y las habilidades que se adquieran facilitan al estudiante prepararse y vivenciar la realidad que lo rodea.

El aporte del siguiente material presenta aspectos de nuestra cultura y permite la interacción de los estudiantes con actividades de dimensión cultural. A partir de una noticia tomada de uno de los periódicos de nuestro país, se elabora la siguiente ficha pedagógica.

\section{Día nacional de la mascarada tradicional costarricense}

"La Giganta, el Diablo, el Jorobado, el Poligordo, la Copetona desfilarán por las calles y avenidas de algunos pueblos con motivo de la celebración del Día de la mascarada costarricense. Los payasos saldrán a festejar su día. Esta tradición data del año 1870 y comenzó en la provincia de Cartago. Esta ciudad albergará el más grande desfile, el 31 de octubre y participarán cimarronas, zancos, bailes típicos y los payasos más famosos y coloridos.

Esta actividad dará inicio a las 9 a. m. en las afueras del cementerio local y terminará en el centro de la ciudad, exactamente en el Mausoleo Florencio del Castillo".

La Nación, jueves 26 de octubre, 2006

1.Público: Adolescentes y adultos

2. Nivel: A2 
3. Tiempo: Tres horas

4. Objetivos lingüísticos:

a. Aplicar la forma del futuro del indicativo

b. Enriquecer el vocabulario relacionado con mascaradas, desfiles y carnaval

c. Identificar la noticia de la prensa escrita.

5. Objetivo comunicativo:

a. Expresar los sentimientos y los valores de las leyendas y las mascaradas.

6. Objetivos culturales:

a. Conocer algunas leyendas de Costa Rica.

b. Descubrir el significado de las mascaradas y de los payasos.

7.Material

a. Noticia del periódico La Nación: Día nacional de la mascarada tradicional costarricense.

b. Papel de colores, goma, tijeras, marcadores, revistas, postales, cromos.

I. Sensibilización

¿Quiénes son estos personajes?

¿Cuáles son las características de cada personaje? ¿Qué representa cada uno de ellos?

II. Comprensión Oral. Recolección de información. El profesor lee la noticia en voz alta y los estudiantes completan la ficha informativa.

Invitación a la celebración de:

Desfilarán: 
El día y la hora de la actividad serán:

El recorrido será:

Los participantes serán:

III. Expresión Oral. Cuéntale a tus compañeros una leyenda de tu país.

IV. Expresión escrita. Vas a celebrar el cumpleaños con una fiesta de disfraces. Antes de ésta, debes confeccionar una invitación, para tus amigos.

V. Comprensión escrita. Se propone la lectura de otra leyenda con sus actividades, por ejemplo: La carreta sin bueyes.

Esta propuesta describe la elaboración y los elementos propios de esta ficha pedagógica. Responde, además, a una evaluación formativa del estudiante en el proceso de aprendizaje y lo hace activo dentro de un contexto cultural. La ficha pedagógica destaca el papel de los profesores como los agentes promotores de la cultura y mediadores para ofrecer a nuestros estudiantes extranjeros lo mejor de lo nuestro. En esta propuesta, el profesor de lengua ha podido reflexionar sobre la importancia del aspecto cultural en clase; y a la vez, ha compartido una propuesta metodológica para enseñar el idioma español y la cultura costarricense a estudiantes extranjeros. El panorama cultural se hace más sencillo y dinámico cuando el profesor toma conciencia de la importancia de utilizar recursos y materiales que involucren lo cultural. La sensibilización del profesor permite y abre espacios a elementos propios de un país, y a la vez enriquece la diversidad y la interculturalidad en las clases de lengua extranjera o segunda lengua. 